\title{
Editorial
}

\section{Working with Faculty}

The topic of this editorial is one that deserves to be revisited and reconsidered frequently. Working with faculty is perhaps one of the more important things that academic librarians do. Realizing that many academic librarians also are faculty, this editorial is focused on those faculty who are not employed in the library.

Peggy Johnson (University of Minnesota Libraries) recently gave a full-day program on the topic of faculty liaison at the University of Michigan Library. She did a commendable job in meeting with different groups to describe the various aspects of this important endeavor. While listening to her, my mind began racing from the primitive days of building liaison with faculty to today and tomorrow's growing sophistication in working with faculty.

In some way, most academic librarians communicate with faculty members. Titles such as bibliographer, coordinator, faculty contact person, faculty liaison, and subject specialist are used to designate those librarians who work more directly with the faculty.

Librarians engage in a broad range of activities with faculty, including selecting paper and electronic resources, designing library instructional programs for students, writing research grants, team-teaching, and a number of other joint endeavors.

E-mail has made a significant difference in the communication between library staff and faculty. Via e-mail, librarians from all areas of the library construct can communicate conveniently with faculty about new acquisitions, different ways to access materials not owned by the library, relevant events being sponsored by the library, and the umpteen other exciting things happening in the library.

\section{Chief Instigators of Use}

Have you ever given serious thought to how much library use would come from stu-

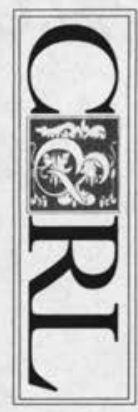
dents without faculty involvement? How many students really and truly use the library for the pure enjoyment of learning? Of course, there are some; but the bulk of students, especially undergraduates, come to the library to check out materials, conduct research, and read materials on reserve as a result of faculty assignments or recommendations. Unfortunately, there is little evidence to support or correlate a student's rate of library use with grade point average. Some bright students have boasted about graduating summa cum laude without setting foot in the library! These students have done themselves a great disservice by not learning the literature and informational resources in their respective disciplines. Notwithstanding the fine work the library staff does with library orientation, we depend on the faculty to make meaningful library assignments in order for students to learn more about the treasures held by the library and the electronic access mechanisms. One of the more important ingredients of education is the stimulation of inquiry; librarians and faculty should do everything possible to encourage the unleashing of this curiosity. Here is where the library is so critical, because it offers answers to a multitude of questions and poses new questions that cry out for answers.

\section{Reeducating the Faculty}

If use of the library's resources is largely dependent on faculty instigation, then we must continuously improve our liaison 
with the faculty. Based merely on the reactions that some academic libraries experienced during the transition from the card catalog to the online catalog, some faculty are not elated about the transformation of the library from reliance on its local paper collection to the emerging dependence on global electronic resources. Speaking flippantly, most of us can say that we know a few faculty who believe the new technology is only a fad that will soon disappear. Speaking earnestly, however, most of the faculty realize that the new information environment is here to stay and look forward to reaping benefits from improvements in the scholarly communication process.

With the unprecedented rate of change we are experiencing with digital/electronic resources, we academic librarians certainly have to "run faster to stay in place." For evidence of this speed of change, we have only to look at the changes that have occurred with the World Wide Web during the past year. Last year's Web has little resemblance to this year's Web! What happened to Gopher? Is Mosaic dead? Will our users be able to find happiness soon on the Web without HTML (hypertext markup language)? How many of our faculty know the Web is hypertext, interactive, and multimedia?

The point I am trying to make is that we have an entirely new domain that requires much work in reeducating the faculty on how to use the scholarly resources. We must become more active in our work with the faculty; we cannot wait for them to come to us. We must take the initiative in inviting ourselves to faculty departmental meetings to talk about the changing information access and delivery systems. If we thought it was discouraging when some faculty showed little interest in the paper collection, we undoubtedly face a larger challenge in introducing faculty to the electronic resources. Issues related to electronic access, site licenses, copyright/intellectual property, network security, certification of information providers, and a Web browser on every desktop are becoming a necessary part of our nomenclature in our work with the faculty.

\section{New Challenges, New Rewards}

It is not uncommon to learn that less than 50 percent of an institution's faculty come to the library on a regular basis. Many faculty who are productive in research and publish frequently in scholarly publications depend on student employees to visit the library to retrieve the necessary resources. With larger numbers of journals and reference books becoming available online and greater desktop availability to electronic resources throughout the world, will we witness even fewer faculty coming to the library? The answer is likely to be "yes." If there is one group of people on our campuses who can truly serve as the "navigators" who locate, filter, and customize information, it is the librarians. We should not only meet this challenge, but exceed the expectations of our user community. There is a long history of faculty respecting and appreciating the fine work of librarians. In the new information environment, we librarians have a grand opportunity to raise our value on campus. Now is the time for us to seize the moment!

DONALD E. RIGGS 


\section{The State}

of the Art

\section{Leaders in the Information}

Industry providing subscription services, article delivery and library automation software.

$\boldsymbol{R E M O}^{\circledR}$ Mouse driven serials management system.

Ross ${ }^{\circledR}$ Online ordering, claiming and searching of journal and publisher databases.

RENEWAL EXPRESS PC-based system to analyze current serials holdings and plan for future collection development.

Financial PlanNer Lotus formatted worksheet to analyze previous spending history and plan future budget allocations.

BACKSERV/BACKMED An Internet list solely devoted to the informal exchange of serial back issues among libraries.

WORLD WIDE WEB

http://www.readmore.com

\section{Readmore ACADEMic SeRVICES}

700 Black Horse Pike, Suite 207

Blackwood, NJ 08012

Phone: 1-800-645-6595

Fax: 609-227-8322 